\title{
CARDIAC CARE IN CULTURAL (CCIC): PELATIHAN MANAJEMEN SERANGAN JANTUNG DENGAN BUDAYA BANJAR "MENYAMAK" BAGI AHLI CABUT ANGIN DI DESA PEMURUS BARU BANJARMASIN
}

\author{
M. Sobirin Mohtar ${ }^{1 *}$, Muhammad Riduansyah ${ }^{2 *}$, Sandi Suwardi $^{3 *}$, Asmadiannor ${ }^{4 *}$ \\ ${ }^{1,2}$ Fakultas Kesehatan Universitas Sari Mulia, Banjarmasin, Indonesia \\ ${ }^{3,4}$ RSUD Ulin, Banjarmasin, Indonesia \\ *email: sobirinmuchtar12345@gmail.com
}

\begin{abstract}
ABSTRAK
Penyakit Jantung masih merupakan salah satu penyebab kematian utama dinegara maju dan berkembang, salah satunya penyakit jantung dengan ACS (Acute Coronary Syndrome). Tingginya angka kematian akibat serangan jantung disebabkan keterlambatan keluarga mendapatkan penanganan yang dipengaruhi oleh beberapa faktor salah satunya adalah kepercayaan. Berdasarkan temuan terdapat tempat pengobatan tradisional pasien serangan jantung di Desa Pemurus Banjarmasin. Sasaran atau mitra dari kegiatan program kemitraan masyarakat ini adalah ahli cabut angin. Kepercayaan yang masih membudaya dimasyarakat terhadap persepsi penyakit jantung diantaranya mengganggap; penyakit menyamak (nyeri dada), masuk angin dan mempercayakan terhadap ahli cabut angin, namun jika hal ini tidak teratasi maka akan berpengaruh terhadap prevalensi kecacatan dan kematian akibat keterlamabatan pertolongan. Maka dari itu, tingginya angka kematian akibat serangan jantung harus dapat dicegah. salah satunya melalui kegiatan Cardiac care in Cultural kepada ahli cabut angin, kader dan masyarakat di Desa Pemurus Baru dengan cara memberikan pelatihan manajemen serangan jantung seperti gejala serangan dan manajemen tindakannya dengan mempertahankan budaya tersebut selama tidak menyimpang dari Kesehatan. Metode pelaksanaan dibagi menjadi 3 (tiga) tahapan; meliputi tahap persiapan dilakukan diskusi dengan mitra untuk merumuskan permasalahan mitra dan solusinya. Tahap pelaksanaan meliputi kegiatan Pelatihan Manajemen Kegawatan dilanjutkan dengan pemberian edukasi kesehatan didampingi oleh fasilitator yang dilaksanakan mulai tanggal 17 Desember 2018 sampai dengan 02 Januari 2019. Hasilnya ada peningkatan pengetahuan dari Sasaran yang diberikan pelatihan pada kelompok ahli cabut angin $(90 \%)$, Kader $(100 \%)$, dan Masyarakat (100\%) telah memahami dengan baik tentang manajemen kegawatan serangan jantung beserta intervensinya setalah diberikan pelatihan dan edukasi kesehatan.
\end{abstract}

Kata Kunci : Cardiac care in Cultural, Ahli cabut angin, Kader, Masyarakat

\section{A. PENDAHULUAN}

Desa Pemurus Baru merupakan salah satu desa yang terletak di J1. Prona II Gg. Tanjung Sari RT. 22 RW. 02 Kel. Pemurus Baru Kec. Banjarmasin Selatan Kabupaten Banjarmasin. Pemurus Baru adalah salah satu kelurahan di Kecamatan Banjarmasin Selatan, Kota Banjarmasin, Provinsi Kalimantan Selatan, Indonesia. Batas-batas wilayah kelurahan Pemurus Baru adalah di bagian utara dan timur kecamatan Banjarmasin timur, 
dibagian selatan kelurahan pemurus

dalam dan dibagian selatan

kelurahan tanjung pagar.

Berdasarkan data Kependudukan dari Desa Pemurus dalam tahun 2020 Jumlah penduduk di desa Pemurus baru berjumlah 7000 jiwa, dengan rincian 3.644 jiwa laki-laki, dan 3.356 jiwa perempuan. Penduduk tersebut terbagi dalam $18 \mathrm{RW}$ dan 65 RT. Jumlah penduduk terbanyak terdapat di Jalan Lembu Jantan dengan jumlah $1.500 \mathrm{KK}$, dengan jumlah penduduk sebanyak 4.909 jiwa. Dua jalan yang lain memiliki jumlah penduduk yang lebih sedikit, yaitu $380 \mathrm{KK}$ pada desa pemurus baru terdiri dari 1.153 orang penduduk.

Penyakit Jantung masih merupakan salah satu penyebab kematian utama dinegara maju dan berkembang, salah satunya penyakit jantung dengan ACS (Acute Coronary Syndrome) (WHO, 2015). Tingginya angka kematian akibat serangan jantung disebabkan keterlambatan keluarga mendapatkan penanganan yang dipengaruhi oleh beberapa faktor salah satunya adalah kepercayaan. (Gayatri et al, 2016; Mohtar M.S et $a l, 2021)$.
Kelly. T and Howie, L. (2010); Herning et al, (2011) menguraikan tingginya angka kematian ACS disebabkan keterlambatan keluarga mendapatkan penanganan dan keterlambatan tersebut dipengaruhi oleh faktor pendidikan, pengetahuan, kepercayaan, emosi, pengalaman sebelumnya pada saat serangan. Agar keterlambatan penanganan tersebut dapat dicegah maka pertolongan pertama first aid participant harus sangat di perhatikan (Ginzburg et al, 2012).

Teori familiy friedman (2010) memandang bahwa keluarga mempunyai tugas dan fungsi utama dalam memutuskan tindakan yang cepat dan tepat. Teori Wholly Compensatory System Orem (2001) memandang bahwa keluarga harus memberikan bantuan sebagian ketika anggota keluarganya sakit (Alligood, M.R, 2014). Teori Cultural care Leininger (2001) memandang bahwa keluarga memilki kecenderungan untuk mempertahankan budayanya pada saat melakukan pertolongan (Leininger, 2010).

Berdasarkan temuan terdapat tempat pengobatan tradisional pasien serangan jantung di Desa Pemurus 
Banjarmasin. Sasaran atau mitra dari kegiatan program kemitraan masyarakat ini adalah ahli cabut angin. Kepercayaan yang masih membudaya dimasyarakat terhadap persepsi penyakit jantung diantaranya mengganggap; penyakit menyamak (nyeri dada), masuk angin dan mempercayakan terhadap ahli cabut angin, namun jika hal ini tidak teratasi maka akan berpengaruh terhadap prevalensi kecacatan dan kematian akibat keterlamabatan pertolongan.

Mohtar, M., S. (2020) Maka dari itu, tingginya angka kematian akibat serangan jantung harus dapat dicegah. salah satunya melalui kegiatan Cardiac care in Cultural kepada ahli cabut angin, kader dan masyarakat di Desa Pemurus Baru dengan cara memberikan pelatihan manajemen serangan jantung seperti gejala serangan dan manajemen tindakannya dengan mempertahankan budaya tersebut selama tidak menyimpang dari Kesehatanan

\section{B. METODE}

Metode pelaksanaan kegiatan dibagi menjadi tiga tahap, yaitu persiapan, pelaksanaan, dan evaluasi. Tahapan persiapan meliputi pendekatan kepada tokoh masyarakat dan petugas kesehatan untuk perizinan terkait penyelenggaraan kegiatan $\mathrm{PkM}$. Selain itu, pada tahap persiapan dilakukan diskusi dengan mitra untuk merumuskan permasalahan yang ada di lingkungan mitra dan solusinya yang ditempuh dengan kegiatan PkM ini.

Kegiatan yang dilakukan berupa pelatihan mengenai cara mengurangi rasa nyeri dengan pelatihan pemberian tehnik relaksasi dan distraksi. Ahli cabut angin Ibu Murdiyana di Jl. Prona II Gg. Tanjung Sari RT 22 RW 02 Kel. Pemurus Baru Kec. Banjarmasin Selatan.

\section{HASIL DAN PEMBAHASAN}

Hasil kegiatan dari PkM yang berjudul "Cardiac Care In Cultural (CCIC): Pelatihan Manajemen Serangan Jantung Dengan Budaya Banjar "Menyamak" Bagi Ahli Cabut Angin Di Desa Pemurus Baru Banjarmasin" diuraikan pada tabel 1.1 . 
Tabel 1.1 Hasil Kegiatan PKM

\begin{tabular}{|c|c|c|c|}
\hline No & Waktu & Kegiatan & Peserta \\
\hline 1 & $\begin{array}{l}17 \text { Desember } \\
2018\end{array}$ & $\begin{array}{l}\text { Pelatihan I (Pertama) } \\
\text { 1. Mengenal Penyakit Jantung } \\
\text { 2. Mengenal Penyenab Serangan } \\
\text { Jantung } \\
\text { 3. Mengenal Gejala Serangan Jantung } \\
\text { 4. Intervensi Keperawatan Serangan } \\
\text { Jantung } \\
\text { 5. Manajemen Kegawatan Serangan } \\
\text { Jantung } \\
\text { 6. Terapi kombinasi CCIC dengan } \\
\text { Tindakan Kesehatan. }\end{array}$ & $\begin{array}{l}15 \text { Ahli Cabut } \\
\text { Angin } \\
3 \text { Kader }\end{array}$ \\
\hline 2 & $\begin{array}{l}19 \text { Desember } \\
2018\end{array}$ & $\begin{array}{l}\text { Focus Group Discussion tentang } \\
\text { demonstrasi pendidikan kesehatan } \\
\text { tentang: Manajemen Kegawatan } \\
\text { Serangan Jantung oleh kader dan ahli } \\
\text { cabut angin }\end{array}$ & $\begin{array}{l}15 \text { Ahli Cabut } \\
\text { Angin } \\
3 \text { Kader }\end{array}$ \\
\hline 3 & $\begin{array}{l}26 \text { Desember } \\
2018\end{array}$ & $\begin{array}{l}\text { Pelatihan Masyarakat tentang: } \\
\text { Kesehatan pada jantung }\end{array}$ & 10 Masyarakat \\
\hline 4 & 02 Januari 2019 & $\begin{array}{l}\text { Pendidikan Kesehatan tentang: } \\
\text { Kesehatan Jantung Masyarakat oleh } \\
\text { Kader dan Ahli cabut angin }\end{array}$ & $\begin{array}{l}15 \text { Ahli Cabut } \\
\text { Angin } \\
3 \text { Kader } \\
10 \text { Masyarakat }\end{array}$ \\
\hline
\end{tabular}

Program Kemitraan

Masyarakat pada Pertemuan pertama Pelatihan materi tentang seputar penyakit jantung seperti mengenal penyakit jantung, mengenal, penyenab serangan jantung, mengenal, gejala serangan jantung, intervensi, keperawatan serangan jantung, manajemen kegawatan serangan jantung (Mohtar, M.,S, Amin F \& Yuandari 2020).

Permahaman masing-masing partisipan yang unik dan beraneka ragam mempersepsikan bahwa serangan ACS di persepsikan budaya banjar dengan istilah Penyakit Menyamak dan budaya jawa dengan istilah Penyakit Angin duduk

Sejalan dengan ungkapan Manggia (2017) bahwa istilah menyamak atau angin duduk sendiri masih rancu atau ambigu, dimana istilah masuk angin sendiri tidak ada dalam istilah medis atau disebut juga dengan isitilah penyakit etnomedisin. (Manggia, 2017 dalam Suara Merdeka; potret komunitas jawa tengah). 
Terapi kombinasi CCIC dengan Tindakan Kesehatan.. Peserta yang hadir 3 (tiga) orang kader posyandu pada pertemuan pertama pelatihan materi yang disampaikan tentang Kesehatan Jantung.

Temuan yang didapatkan menunjukkan bahwa Tindakan pertama yang dilakukan partisipan dalam melakukan pertolangan pada anggota keluarganya yang mengalami serangan jantung yaitu dengan pengobtan alternatif melalu cara pemijatan, pengusapan dan penggunaan krim pereda nyeri. Pengobatan alternatif berupa pemijatan atau masase sangat bermanfaat dalam mengobati nyeri namun berbeda jika nyeri tersebut mengarah kepada penyakit kegawatan seperti nyeri dada karena penyakit jantung, mengenai hal tersebut seharusnya keluarga memainkan tugas dan fungsinya sebagai keluarga bahwa keluarga harus bisa mencegah dan memperbaiki masalah-masalah yang ada dalam kelompoknya.

Sejalan dengan teori Friedman $e t$ al, (2010) bahwa keluarga harus melaksanakan perawatan atau pemeliharaan kesehatan dapat dilihat dari tugas kesehatan keluarga dalam hal ini mengenal masalah kesehatan keluarga membuat keputusan untuk tindakan kesehatan yang tepat, menggunakan fasilitas kesehatan yang ada di masyarakat, mempertahankan suasana rumah yang sehat dan memberikan perawatan kepada anggota keluarga yang sakit.

Sebelum dan sesudah kegitatan penyampaian materi dilakukan Tanya jawab secara lesan. Hasilnya ada peningkatan pengetahuan dari para peserta sesudah mengikuti pelatihan. Peserta memperhatikan dan mengikuti acara pelatihan sampai selesai. Pengobatan alternatif baik teknik pemijatan maupun pengolesan menggunakan bahan dasar sirih sebagai bahan dasar yang di percaya kandungan didalamnya terdapat senyawa kimia yang selain sebagai antibiotik terbanyak juga sebagai aroma terapi dan penghangat tubuh. Sejalan dalam penelitian Mulyono (2005) Daun sirih juga mengandung minyak atsiri (pemberi aromatic khas).

Pada pengobatan tradisional khususnya dalam mengobati rasa nyeri daun sirih dikenal sebagi zat 
aromatik

yang

dapat

mengahangatkan tubuh sehingga dari rasa hangat tadi mapu menghambat rasa nyeri dan mencegah rasa nyeri itu menjalar. Mattheus dalam Ali (2010) menyatakan dalam argumen yang disampaikannya dalam pertemuan tahunan "The American Psychiatric Association", bahwa mungkin suatu saat kita para dokter akan menuliskan do ${ }^{\text {ee } a ~ p a d a ~ k e r t a s ~}$ resep selain resep obat untuk pasien. Karena dari studi yang telah dilakukan oleh para ahli, ternyata $72 \%$ menyatakan bahwa komitmen agama (doa) menunjukkan pengaruh positif pada pasien

Program Kemitraan Masyarakat pada pertemuan kedua ialah Focus Group Discussion tentang demonstrasi pendidikan kesehatan tentang: Manajemen Kegawatan Serangan Jantung oleh Kader Posyandu dan Ahli cabut angin. Program Kemitraan Masyarakat pada pertemuan kedua pelatihan materi yang disampaikan tentang Focus Group Discussion tentang demonstrasi pendidikan kesehatan tentang: Cardiac care in cultural oleh Kader Posyandu dan ahli cabut angin dengan pendampingan.
Sebelum dan sesudah kegiatan dilakukan Tanya jawab secara lesan. Hasilnya ada peningkatan pengetahuan dari para peserta sesudah mengikuti pelatihan.

Kader yang diberikan pelatihan $100 \%$ sementara ahli cabut nagin 90\% telah memahami dengan baik tentang kesehatan jantung Seluruh kader juga mampu melakukan penyuluhan mandiri setelah diberikan pelatihan. Pelatihan merupakan salah satu cara dalam meningkatkan pengetahuan dan kemampuan seseorang terkait suatu kegiatan (Pratiwi, 2011).

Program Kemitraan Masyarakat pada pertemuan ketiga ialah Pelatihan Masyarakat tentang: Kesehatan Jantung Masyarakt Peserta yang hadir 10 (sepuluh) orang masyarakat pada pertemuan ketiga pelatihan materinya adalah Pelatihan tentang Kesehatan jantung. Peserta memperhatikan dan mengikuti acara pelatihan sampai selesai. Hasil observasi peserta dapat menjawab pertanyaan dari fasilitator. Program Kemitraan Masyarakat pada pertemuan ke empat Kader dan Ahli Cabut angin memberikan pendidikan kesehatan pada remaja 
dengan pendampingan. Peserta yang hadir kader kesehatan reproduksi remaja 10 (sepuluh) orang. Kader dan ahli cabut angin sudah bisa memberikan pendidikan kesehatan hanya untuk pengembangan materi masih dilakukan oleh fasilitator. Menjawab pertanyaan dari peserta belum begitu tepat sehingga fasilitator yang membantu menjawab, tetapi sudah berani dan percaya diri untuk melakukan pendidikan kesehatan kepada kelompok remaja, karena untuk menghindari salah persepsi dari para remaja.

Hal ini sesuai dengan pernyataan Sunaryo \& lestari, (2015) bahwa Kurangnya informasi tentang kesehatan jantung dapat memberikan dampak pada masayarakat seperti kurang memiliki pengetahuan yang memadai dalam menghadapi perubahan dan masalah yang mungkin bisa terjadi pada masyarakat sehingga dapat terjadi kesalahan persepsi pada masyakarat tentang kesehatan jantung (Pratiwi, 2011).

Pada kelompok masyarakat terjadi peningkatan pengetahuan $(85 \%)$ menjadi lebih baik tentang kesehatan jantung setelah diberikan penyuluhan kesehatan. Temuan ini sejalan dengan temuan Sunaryo \& lestari (2015) bahwa penyuluhan dengan metode FGD dapat meningkatkan pengetahuan.

Kegiatan PkM ini telah terlaksana dengan baik yang telah didukung melalui keterlibatan para kader kesehatan, ahli cabut angin dan masyarakat. Hasil kegiatan PkM yang sudah dilaksanakn diharapkan dapat menjadi bekal untuk melanjutkan PkM dan programprogram yang sebelumnya sudah ada dan berlangsung di Desa Pemurus Baru yang berkaitan dengan Cardiac Care in Cultural atau tentang Perawatan Jantung dari sudut pandang budaya. Dengan adanya program PkM ini, diharapkan kader kesehatan mampu bekerjasama dengan karang taruna dalam penyebarluasan informasi yang berkaitan dengan Cardiac Care in Cultural atau tentang Perawatan Jantung dari sudut pandang budaya di masyarakat. Kader kesehatan merupakan salah satu target utama dalam kegiatan PkM ini. Dengan adanya kegiatan ini, diharapkan kader dapat meningkatkan 
kemampuan serta pemahaman terkait

Cardiac Care in Cultural atau tentang Perawatan Jantung dari sudut pandang budaya di masyarakat.

Selain itu diharapkan kader kesehatan dan ahli cabut angin dapat melakukan sosialisasi kepada masyarakat sekitar setelah mendapatkan pelatihan dan pendidikan kesehatan dalam program ini. Hal tersebut diharapkan dapat memaksimalkan peran kader kesehatan di masyarakat dan dapat membantu merubah pola pikir dan pola hidup masyarakat untuk meningkatkan pengetahuan masyarakat tentang Cardiac Care in Cultural atau tentang Perawatan Jantung dari sudut pandang budaya di masyarakat dengan harapan akan menurunkan angka kematian pada pasien dengan Riwayat serangan jantung.

Masyarakat juga menjadi target utama selain kader posyandu dan Ahli cabut angin dengan harapan karang taruna sebagai remaja akan lebih memahami tentang Cardiac Care in Cultural atau tentang Perawatan Jantung dari sudut pandang budaya di masyarakat sehingga mampu menerapkan pengetahuan yang telat diperoleh melalui pelatihan maupun pendidikan kesehatan. Selain itu juga bisa memberikan informasi kepada remaja yang lainnya dan juga kepada orang tua sehingga dengan harapan akan berdampak pada penurunan angka kejadian kesakitan dan kematian yang banyak resiko terhadap kesehatannya.

\section{KESIMPULAN}

Hasil dari pelaksanaan kegiatan pelatihan teknik relaksasi dan distraksi untuk mengurangi nyeri dada untuk ahli cabut angin tradisional khas budaya banjar yang dilaksanakan di rumah pak RT Bapak Nuriansyah dan Ahli Cabut Angin Ibu Murdiyana Jl. Prona II Gg. Tanjung Sari RT. 22 RW. 02 Kel. Pemurus Baru Kec. Banjarmasin Selatan Kegiatan ini berjalan dengan lancar sesuai dengan apa yang diharapkan dan sasaran mampu memahami teknik relaksasi dan distraksi tersebut dibuktikan dengan antusias ahli cabut angin dan warga saat dilaksanakan sesi demonstrasi teknik relaksasi dan distraksi. Dalam proses pelatihan ini terjadi interaksi antara panitia dengan ahli cabut angin dibuktikan dengan 
ahli cabut angin dapat menjelaskan cara menyamak khas budaya banjar kepada panitia. Kendala pada pelatihan ini adalah keterbatasan waktu dalam pemberian kesempatan pada ahli cabut angin dan warga untuk bertanya. Saran yang dapat kami sampaikan setelah dilakukan

\section{DAFTAR PUSTAKA}

Alligood, M.R. (2014). Nursing Theorists and Their Work: Madeleine M.Leininger: Culture Care Thory of Diversity and Universality:417 $\left(8^{\text {th }} E d\right)$. St. Louis : Mosby-Elseiver

Ali, Zaidin. (2010). Agama, Kesehatan dan Keperawatan. Jakarta: CV Trans Info Media.

Friedman, M.M (2010). Family Nursing : Research Theory, Practice. 5th edition. Prentice Hall, New Jersey.

Gayatri et al. (2016). Prediktor Mortalitas Dalam-Rumah-Sakit Pasien Infark Miokard ST Elevation (STEMI) Akut di RSUD dr. Dradjat Prawiranegara Serang, Indonesia. CDK-238/ vol.43 no. 3 , th. 2016

Ginzburg et al. (2012). The Analysis Of Factors Influencing The Terms Of Hospital Admission In Patients With Acute Coronary Syndrom (According To The Lis Study Data - Lyubertsy Study On kegiatan pelatihan ini adalah pengetahuan tentang teknik relaksasi dan distraksi untuk mengurangi nyeri dada cara menggunakannya dapat disebarluaskan kepada semua ahli cabut angin sebagai salah satu cara untuk mencegah terjadinya nyeri yang hebat pada angina pektoris.

Mortality Rate In Patients After Acute Myocardial Infarction).РациональнаяФарм акотерапия в Кардиологии ;8(2).

Herning et al. (2011). Women's experiences and behavi our at onset of symptoms of ST segment elevation acute myocardial infarction. Elsevier. European Journal of Cardiovascular Nursing, 10, pp.241-247.

Kelly. T and Howie, L. (2010). Working with stories in nursing research: procedures used in narrative analysis. International journal of mental health nursing,16,pp.136-144. doi :10.1111/J.14470349.2007.00457.x

Leininger, Medeleine M. (2001). Transcultural Nursing: Concept. Theorist. Research \& Practice. $3^{\text {rd }}$ Edition. USA: McGraw-Hill

Leininger., M., M. (2010).Transcultural Nursing: Concept.Theorist. 
Research \& Practice. $3^{\text {rd }}$ Edition. USA: McGraw-Hill

Manggia. (2017). Penyakit Jantung Kerap disebut Angin duduk. Suara Merdeka [on-line].

Diakses pada tanggal 15 Januari 2018 dari. https://ikapesta.com/wpcontent/ uploads/.../ Mengenal-EfekSpesial-dalam-Pesta.pdf

Mohtar, M., S. (2020). Culture Care Applications in Family First Aid to The Patients With Heart Attack. European Alliance for Innovation. ISBN 978-1-63190257-4 ISSN 2593-7 http://dx.doi.org/10.4108/eai.2311-2019.2298392

Mohtar, M.,S et al. (2021). The First Response of Family to Patient with Heart Attack in Banjarese Community South Kalimantan: A Phenomenological Study. International Journal of Clinical Inventions and Medical Sciences. Vol3 (2):67-77. p-ISSN: 27214737, e-ISSN: 2721-7302. DOI:10.36079/lamintang.ijcims0302.248
Mohtar, M.,S, Amin F \& Yuandari. (2021). Principles Of Patient Centered Care (PCC) In Emergency Nursing Care Cardiovascular Activity Case. Caring Nursing Journal. ISSN: 2580-0078.Vol.5.No.1. journal.umbjm.ac.id/index.php/c aring-nursing

Mulyono. (2005). Khasiat dan Manfaat daun sirih: Obat Mujarab dari masa ke masa. Jakarta: Agro Media Pustaka.

Pratiwi.(2011).Buku Ajar Keperawatan Transkultural. Yogyakarta: Gosyen Publishing, 2011.

Orem, D.E. (2001). Nursing : Concepts of Practice $\left(6^{\text {th }}\right.$ ed.). St. Louis : Mosby

Sunaryo \& lestari (2015). Pengaruh Relaksasi Benson Terhadap Penurunan Skala Nyeri Dada Kiri Pada Pasien Acute Myocardial Infark Di Rs Dr Moewardi Surakarta. Jurnal Terpadu Ilmu Kesehatan, Volume 4, No 2,pp.82-196. 